УДК 575.224.22

\title{
ПОЛИМОРФИЗМ ГЕНА РЕЦЕПТОРА ВИТАМИНА D У КОРЕННОГО НАСЕЛЕНИЯ СИБИРИ
}

\author{
Малярчук Б. А. \\ ФГБУН Институт биологических проблем Севера ДВО РАН, г. Магадан \\ E-mail: malyarchuk@ibpn.ru
}

\begin{abstract}
На основе собственных и литературных данных о полноэкзомном полиморфизме у коренного населения Сибири исследована изменчивость гена рецептора витамина $\mathrm{D}$ (гена $V D R$ ), играющего большую роль в процессах обмена кальция и фосфора, транспорта кальция в костную ткань, иммуномодуляции и регуляции энергетического метаболизма клетки. В экзонах полиморфизм обнаружен в двух позициях: синонимичная замена в экзоне 9 (rs731236-G) и несинонимичная замена в экзоне 2 (rs2228570-G), имеющая функциональное значение. Наиболее высокие частоты варианта rs $2228570-\mathrm{G}(81 \%)$ зарегистрированы в центрально-сибирской выборке (эвены, эвенки, якуты), самые низкие (57\%) в выборке из Северо-Восточной Сибири (эскимосы, чукчи и коряки) и промежуточные (61 и $63 \%$, соответственно) в южно-сибирской (тувинцы, шорцы, алтайцы, буряты) и западно-сибирской (кеты, ханты, манси, селькупы, ненцы, нганасане) выборках. Максимальная частота гомозиготного генотипа rs2228570-GG (69\%) выявлена в центрально-сибирской выборке. Встречаемость вариантов полиморфизма гена $V D R$ в популяциях коренного населения Сибири обсуждается в связи с адаптацией к различным экологическим условиям.
\end{abstract}

Ключевые слова: генетический полиморфизм, ген рецептора витамина D (VDR), полиморфизм локуса rs2228570, популяции человека, Сибирь.

DOI: 10.34078/1814-0998-2020-3-120-127

Дефицит витамина D характерен для населения всех регионов России, и значительную роль в развитии этого состояния играет полиморфизм гена рецептора витамина $\mathrm{D}$ (гена $V D R$ ) в популяциях человека (Козлов и др., 2013, 2016; Батурин и др., 2017). Ген VDR имеет длину примерно 100 тыс. пар нуклеотидов, расположен на хромосоме 12 и представлен 14 экзонами, подразделенными на два основных домена. Первые шесть экзонов (1a-1f) находятся в промоторном регионе гена и участвуют в альтернативном сплайсинге, а остальные экзоны (экзоны 2-9) локализованы в кодирующей области и присутствуют во всех 14 обнаруженных вариантах транскриптов гена VDR (Zenata, Vrzal, 2017). Известны также три изоформы рецептора витамина D: две из них (длинная VDRB1 и короткая VDRA) формируются в результате альтернативного сплайсинга, а третья, еще более короткая (так называемый FokI-вариант VDRA), появляется вследствие нуклеотидной замены в кодоне, ответственном за инициацию трансляции (локус rs2228570 экзона 2) (Ames et al., 1999; Jurutka et al., 2000).

(C) Малярчук Б. А., 2020
Рецепторы витамина D активируются кальцитриолом (активной гормональной формой витамина $\mathrm{D}$, или $\left.1.25(\mathrm{OH})_{2} \mathrm{D}\right)$, который синтезируется из транспортной формы 25-гидроксивитамина $\mathrm{D}$ (или 25(OH)D). В свою очередь $25(\mathrm{OH}) \mathrm{D}$ формируется либо из холекальциферола D3, который синтезируется в коже под воздействием ультрафиолета, либо из поступающего с пищей витамина D2. Поскольку на территории Северной Евразии (севернее $35^{\circ}$ с. ш.) уровень ультрафиолетового излучения недостаточен для круглогодичного синтеза холекальциферола D3 в коже, то большое значение на севере Евразии приобретает экзогенное потребление человеком витаминов D2 и D3 (Козлов, Атеева, 2011). Вместе c тем обнаружено, что различия по уровню витамина D в сыворотке крови (по концентрации $25(\mathrm{OH}) \mathrm{D})$ могут определяться полиморфными вариантами гена $V D R$. Так, у населения ЯмалоНенецкого автономного округа дефицит витамина $\mathrm{D}$ в крови выявляется преимущественно у носителей аллеля $\mathrm{G}$ в локусе rs2228570 (Батурин и др., 2017). Кроме этого, известно, что носители аллеля rs 2228570-G характеризуются большей степенью абсорбции кальция и минеральной плотности костей, чем носители аллеля A (Arai 
et al., 1997; Ames et al., 1999). Результаты исследований полиморфизма гена $V D R$ в популяциях показали, что адаптация к условиям природной среды также играла значительную роль в распространении определенных полиморфных вариантов этого гена. Так, например, в экологических условиях с низкой доступностью витамина $\mathrm{D}$ и продуктов питания, содержащих кальций, в популяции шорцев Южной Сибири увеличивается частота тех вариантов полиморфизма (в том числе аллеля rs2228570-G), которые обеспечивают повышение чувствительности рецепторов тканей к витамину D (Козлов и др., 2019).

Установлено, что рецепторы VDR играют важную роль в модуляции транскрипции целого ряда генов, ответственных за многие процессы (такие, как всасывание кальция и фосфора в кишечнике, транспорт кальция в костную ткань, иммуномодуляция и др.) (Arai et al., 1997; Zenata, Vrzal, 2017). Воздействие VDR на экспрессию белков митохондрий указывает на участие этого рецептора и его генетических вариантов в регуляции энергетического метаболизма клетки, что имеет смысл учитывать в исследованиях адаптации популяций человека к условиям Крайнего Севера (Громова и др., 2016). Однако, несмотря на столь большое значение, исследования полиморфизма гена $V D R$ в российских популяциях проводились довольно фрагментарно и охватывали, главным образом, несколько полиморфных вариантов (rs2228570 и rs 1544410 , в основном) (Козлов и др., 2013, 2016, 2019; Батурин и др., 2017). В настоящей работе представлены результаты анализа полиморфизма гена $V D R$ у коренного населения Сибири на основе данных о полноэкзомном полиморфизме (Clemente et al., 2014; Малярчук и др., 2016; Pagani et al., 2016).

\section{МАТЕРИАЛ И МЕТОДЫ}

Проанализированы опубликованные ранее с участием автора настоящей работы данные о полноэкзомном полиморфизме в популяциях коренного населения Северо-Восточной Сибири (эскимосы, чукчи, коряки; $\mathrm{N}=25$ ), Центральной Сибири (эвены, эвенки, якуты; $\mathrm{N}=29$ ), Южной Сибири (тувинцы, шорцы, алтайцы, буряты; $\mathrm{N}=$ 28 ) и Западной Сибири (кеты, ханты, манси, селькупы, ненцы, нганасаны; N = 20) (Clemente et al., 2014; Pagani et al., 2016). Выполнен анализ полиморфизма всех экзонов и прилегающих к ним участков интронов гена $V D R$, расположенного на хромосоме 12 между позициями 48235320 и 48336831. Нумерация нуклеотидов приводится согласно референтной последовательности генома человека GRCh37.p13 (hg19).

Для анализа полиморфизма локуса rs 2228570 дополнительно использовали результаты экзомного секвенирования шести образцов ДНК от представителей коренного населения СевероЭвенского района Магаданской области (3 коряка и 2 эвена) и Эвенкийского автономного округа (1 эвенк) (Малярчук и др., 2016).

Для выявления гаплотипов из генотипов гена $V D R$ с неизвестной гаметной фазой применяли алгоритм ELB пакета программ Arlequin 3.01 (Excoffier et al., 2007). Статистическую значимость различий частот аллелей и генотипов анализируемых локусов гена $V D R$ в сравниваемых группах определяли с помощью точного критерия Фишера. Степень межпопуляционной дифференциации по частотам вариантов гена $V D R$ оценивали с помощью значений $\mathrm{F}_{\mathrm{ST}}$ (Arlequin 3.01). Coответствие распределения генотипов в популяциях равновесию Харди - Вайнберга рассчитывали с помощью пакета программ Arlequin 3.01.

\section{РЕЗУЛЬТАТЫ И ОБСУЖДЕНИЕ}

Анализ нуклеотидных последовательностей экзонов и прилегающих к ним некодирующих участков гена $V D R$ у 102 представителей различных этнических групп коренного населения Сибири показал наличие полиморфизма в 12 нуклеотидных позициях (табл. 1). Однако в экзонах обнаружены только две нуклеотидные замены. В экзоне 2 - это несинонимичная замена rs 2228570-G, приводящая к аминокислотной замене Met51 Thr, и в экзоне 9 - синонимичная замена rs731236-G (аминокислотная позиция Ile402). Все остальные полиморфные варианты зарегистрированы в некодирующей области (в 3'- и 5'нетранслируемых участках и интронах гена).

Как видно из табл. 2, все выявленные у коренного населения Сибири варианты полиморфизма ранее уже были обнаружены у населения Восточной Азии, за исключением единственного варианта rs192488130-Т. Этот вариант полиморфизма с низкой частотой присутствует у коряков, эвенков и якутов, а по сведениям базы данных dbSNP (www.ncbi.nlm.nih.gov/projects/SNP) среди населения мира ранее был обнаружен только у американских индейцев (с частотой примерно 1\%).

Из нуклеотидных замен наиболее интересна транзиция $\mathrm{A} \rightarrow \mathrm{G}$ в локусе $\mathrm{rs} 2228570$, которая приводит к утрате стартового кодона трансляции, в связи с чем синтезируется укороченный, но более активный вариант изоформы VDRA (Ames et al., 1999). В табл. 3 приводятся данные о распространенности аллелей и генотипов по локуcy rs2228570 в популяциях Сибири. Как видно, частота варианта rs $2228570-\mathrm{G}$ в региональных выборках варьирует от 57\% в Северо-Восточной Сибири (у эскимосов, чукчей и коряков) до $81 \%$ в Центральной Сибири (у эвенов, эвенков и якутов). В среднем в Сибири частота варианта rs 2228570-G составила $66 \%$, что несколько выше средней по Восточной Азии (58\% по данным dbSNP). 
Таблица 1. Полиморфизм гена VDR у коренного населения Сибири

Table 1. Polymorphism of the VDR gene in aboriginal populations of Siberia

\begin{tabular}{|l|c|c|c|c|}
\hline № & $\begin{array}{c}\text { Нуклеотидная } \\
\text { позиция }\end{array}$ & $\begin{array}{c}\text { Идентификатор } \\
\text { полиморфизма }\end{array}$ & Локализация замены & Тип замены \\
\hline 1 & 48236386 & rs2853562 & 3'-utr $^{\prime}$ & $\mathrm{T} \rightarrow \mathrm{A}$ \\
\hline 2 & 48236623 & rs9729 & 3'-utr & $\mathrm{G} \rightarrow \mathrm{T}$ \\
\hline 3 & 48237210 & rs11574131 & 3'-utr & $\mathrm{G} \rightarrow \mathrm{A}$ \\
\hline 4 & 48237303 & rs11574129 & 3'-utr & $\mathrm{A} \rightarrow \mathrm{G}$ \\
\hline 5 & 48238068 & rs3847987 & 3'-utr & $\mathrm{C} \rightarrow \mathrm{A}$ \\
\hline 6 & 48238221 & rs739837 & 3'-utr & $\mathrm{G} \rightarrow \mathrm{T}$ \\
\hline 7 & 48238757 & rs731236 & Экзон 9 & $\mathrm{A} \rightarrow \mathrm{G}$ \\
\hline 8 & 48272743 & rs10783218 & Интрон & $\mathrm{G} \rightarrow \mathrm{A}$ \\
\hline 9 & 48272895 & rs2228570 & Экзон 2 & $\mathrm{A} \rightarrow \mathrm{G}$ \\
\hline 10 & 48293716 & rs11168293 & 5'-utr & $\mathrm{G} \rightarrow \mathrm{T}$ \\
\hline 11 & 48295133 & rs12581281 & Интрон & $\mathrm{C} \rightarrow \mathrm{T}$ \\
\hline 12 & 48298692 & rs192488130 & Интрон & $\mathrm{A} \rightarrow \mathrm{T}$ \\
\hline
\end{tabular}

Примечание. Тип замены показан в направлении от предкового к производному варианту. 3'-utr и 5'-utr - 3'- и 5'- нетранслируемые области гена VDR.

Таблица 2. Распространенность вариантов полиморфизма гена VDR в популяциях Сибири и Восточной Азии

Table 2. Distribution of polymorphic variants of the VDR gene in populations of Siberia and East Asia

\begin{tabular}{|l|c|c|c|c|c|c|}
\hline \multirow{2}{*}{$\begin{array}{c}\text { Вариант } \\
\text { полиморфизма }\end{array}$} & $\begin{array}{c}\text { СВС } \\
(\mathrm{N}=25)\end{array}$ & $\begin{array}{c}\text { ЦС } \\
(\mathrm{N}=29)\end{array}$ & $\begin{array}{c}\text { ЮС } \\
(\mathrm{N}=28)\end{array}$ & $\begin{array}{c}3 \mathrm{C} \\
(\mathrm{N}=20)\end{array}$ & $\begin{array}{c}\text { Сибирь } \\
\text { в целом } \\
(\mathrm{N}=102)\end{array}$ & $\begin{array}{c}\text { Восточная Азия } \\
(\mathrm{N}=1008)^{*}\end{array}$ \\
\hline rs2853562-A & 34.0 & 36.2 & 39.3 & 57.5 & 40.7 & 29.1 \\
\hline rs9729-T & 34.0 & 36.2 & 39.3 & 57.5 & 40.7 & 29.1 \\
\hline rs11574131-A & 2.0 & 3.4 & 7.1 & 7.5 & 4.9 & 1.6 \\
\hline rs11574129-G & 14.0 & 13.8 & 14.3 & 22.5 & 15.7 & 14.2 \\
\hline rs3847987-A & 28.0 & 27.6 & 25.0 & 30.0 & 27.5 & 21.6 \\
\hline rs739837-T & 34.0 & 36.2 & 39.3 & 40.7 & 40.7 & 29.1 \\
\hline rs731236-G & 4.0 & 8.6 & 14.3 & 22.5 & 11.8 & 6.7 \\
\hline rs10783218-A & 2.0 & 1.7 & 0 & 2.5 & 1.5 & 5.6 \\
\hline rs2228570-G & 60.0 & 81.0 & 58.9 & 62.5 & 66.2 & 58.2 \\
\hline rs11168293-T & 20.0 & 15.5 & 3.6 & 22.5 & 14.7 & 1.7 \\
\hline rs12581281-T & 2.0 & 3.4 & 8.9 & 2.5 & 4.4 & 13.9 \\
\hline rs192488130-T & 2.0 & 5.2 & 0 & 0 & 2.0 & 0 \\
\hline
\end{tabular}

Примечание. Приводятся частоты производных вариантов полиморфизма согласно данным табл. 1. Сокращения: СВС - Северо-Восточная Сибирь, ЦС - Центральная Сибирь, ЮС - Южная Сибирь, 3С Западная Сибирь.

*Источник: база данных dbSNP (www.ncbi.nlm.nih.gov/projects/SNP).

Анализ распределения генотипов показал, что наиболее высокие частоты генотипа rs2228570GG наблюдаются в выборке из Центральной Сибири (69\%). Вместе с тем достоверных отклонений от равновесия Харди - Вайнберга в популяциях не обнаружено (см. табл. 3). $\mathrm{F}_{\mathrm{ST}}$-анализ рас- пределения частот генотипов локуса rs2228570 показывает, что только центрально-сибирская выборка статистически значимо $(\mathrm{p}<0.05)$ отличается от всех остальных сибирских выборок (значения $\mathrm{F}_{\mathrm{ST}}$ варьируют от 6.8 до 11.5\%), которые между собой не различаются $\left(\mathrm{F}_{\mathrm{ST}} \sim 0 \%\right)$. 
Таблица 3. Частоты генотипов и аллелей локуса rs2228570 у коренного населения Сибири

Table 3. Frequencies of genotypes and alleles of the rs2228570 locus in aboriginal populations of Siberia

\begin{tabular}{|c|c|c|c|c|c|c|c|c|c|}
\hline \multirow{2}{*}{ Популяции } & \multirow{2}{*}{$\mathrm{N}$} & \multicolumn{3}{|c|}{ Генотипы } & \multicolumn{2}{|c|}{ Аллели } & \multirow{2}{*}{ Но } & \multirow{2}{*}{$\mathrm{He}$} & \multirow{2}{*}{ HWE, p } \\
\hline & & AA & AG & GG & A & $\mathrm{G}$ & & & \\
\hline Северо-Восточная Сибирь & 28 & 0.14 & 0.57 & 0.29 & 0.43 & 0.57 & 0.57 & 0.5 & 0.47 \\
\hline Центральная Сибирь & 32 & 0.06 & 0.25 & 0.69 & 0.19 & 0.81 & 0.25 & 0.31 & 0.27 \\
\hline Южная Сибирь & 28 & 0.14 & 0.5 & 0.36 & 0.39 & 0.61 & 0.5 & 0.49 & 1.0 \\
\hline Западная Сибирь & 20 & 0.1 & 0.55 & 0.35 & 0.37 & 0.63 & 0.55 & 0.48 & 0.65 \\
\hline Сибирь в целом & 108 & 0.11 & 0.45 & 0.44 & 0.34 & 0.66 & 0.45 & 0.45 & 1.0 \\
\hline
\end{tabular}

Примечание. N - размер выборки исследованных индивидуумов; Но и Не - наблюдаемая и ожидаемая гетерозиготность, соответственно; HWE, p - статистическая значимость отклонения от равновесия Харди - Вайнберга (достоверно при $\mathrm{p}<0.05$ ).

Как видно из табл. 3, частота варианта rs2228570-G достаточно высока во всех исследованных выборках коренного населения Сибири. Между тем анализ гаплотипов, сформированных аллельными вариантами изученных локусов, по- казывает, что вариант rs2228570-G обнаруживается на различных гаплотипах и не ассоциируется с распространением в популяциях какой-либо одной группы гаплотипов (табл. 4). По данным табл. 4 наблюдаются две основные группы гапло-

\section{Таблица 4. Частота (в \%) гаплотипов гена VDR у коренного населения Сибири}

Table 4. Frequency (\%) of the VDR gene haplotypes in aboriginal populations of Siberia

\begin{tabular}{|c|c|c|c|c|c|c|c|c|c|c|c|c|c|c|c|c|}
\hline \multirow{2}{*}{ № } & \multicolumn{12}{|c|}{ Полиморфные локусы } & \multicolumn{4}{|c|}{ Популяции } \\
\hline & 1 & 2 & 3 & 4 & 5 & 6 & 7 & 8 & 9 & 10 & 11 & 12 & $\mathrm{CBC}$ & ЦС & ЮC & $3 \mathrm{C}$ \\
\hline 1 & $\mathrm{~T}$ & G & $\mathrm{G}$ & $\mathrm{A}$ & C & G & A & $\mathrm{G}$ & $\mathrm{A}$ & $G$ & $\mathrm{C}$ & A & 36.0 & 10.3 & 21.4 & 2.5 \\
\hline 2 & $\mathrm{~T}$ & $\mathrm{G}$ & G & A & C & $G$ & A & $\mathrm{G}$ & $\mathbf{G}$ & $\mathrm{G}$ & $\mathrm{C}$ & A & 26.0 & 44.8 & 30.4 & 30.0 \\
\hline 3 & $T$ & $\mathrm{G}$ & $G$ & A & $\mathrm{C}$ & $G$ & $\mathrm{~A}$ & $\mathrm{G}$ & $\mathbf{G}$ & $G$ & $\mathrm{~T}$ & $\mathrm{~A}$ & 0 & 0 & 8.9 & 0 \\
\hline 4 & $\mathrm{~T}$ & $\mathrm{G}$ & $G$ & A & $\mathrm{C}$ & $G$ & $\mathrm{~A}$ & $G$ & $\mathbf{G}$ & $\mathrm{T}$ & $\mathrm{C}$ & $\mathrm{A}$ & 2.0 & 3.4 & 0 & 0 \\
\hline 5 & $\mathrm{~T}$ & $\mathrm{G}$ & $G$ & $\mathrm{~A}$ & $\mathrm{C}$ & $G$ & $\mathrm{~A}$ & $\mathrm{G}$ & $\mathbf{G}$ & $\mathrm{T}$ & $\mathrm{C}$ & $\mathrm{T}$ & 0 & 5.2 & 0 & 0 \\
\hline 6 & $\mathrm{~T}$ & $\mathrm{G}$ & G & A & C & $G$ & A & G & A & $\mathrm{T}$ & $\mathrm{C}$ & A & 0 & 0 & 0 & 7.5 \\
\hline 7 & $\mathrm{~T}$ & $\mathrm{G}$ & $G$ & $\mathrm{~A}$ & $\mathrm{C}$ & $G$ & $\mathrm{~A}$ & $\mathrm{~A}$ & $\mathrm{~A}$ & $G$ & $\mathrm{C}$ & $\mathrm{A}$ & 0 & 0 & 0 & 2.5 \\
\hline 8 & $\mathrm{~T}$ & $\mathrm{G}$ & $G$ & $\mathrm{~A}$ & $\mathrm{C}$ & G & $\mathrm{A}$ & $\mathrm{A}$ & $\mathbf{G}$ & $G$ & $\mathrm{C}$ & $\mathrm{A}$ & 2.0 & 0 & 0 & 0 \\
\hline 9 & $\mathrm{~A}$ & $\mathrm{~T}$ & $G$ & $\mathrm{~A}$ & C & $\mathrm{T}$ & $\mathrm{A}$ & $G$ & $\mathrm{~A}$ & $G$ & $\mathrm{C}$ & $\mathrm{A}$ & 2.0 & 0 & 0 & 0 \\
\hline 10 & A & $\mathrm{T}$ & G & A & C & $\mathrm{T}$ & A & G & G & $\mathrm{T}$ & $\mathrm{C}$ & A & 0 & 0 & 0 & 2.5 \\
\hline 11 & $\mathrm{~A}$ & $\mathrm{~T}$ & G & $\mathrm{A}$ & $\mathrm{C}$ & $\mathrm{T}$ & G & G & $\mathrm{A}$ & $\mathrm{G}$ & $\mathrm{C}$ & $\mathrm{A}$ & 0 & 0 & 12.5 & 5.0 \\
\hline 12 & $\mathrm{~A}$ & $\mathrm{~T}$ & G & $\mathrm{A}$ & $\mathrm{C}$ & $\mathrm{T}$ & G & G & $\mathrm{A}$ & $\mathrm{G}$ & $\mathrm{T}$ & $\mathrm{A}$ & 0 & 0 & 0 & 2.5 \\
\hline 13 & $\mathrm{~A}$ & $\mathrm{~T}$ & G & $\mathrm{A}$ & $\mathrm{C}$ & $\mathrm{T}$ & G & G & $\mathbf{G}$ & $\mathrm{G}$ & $\mathrm{C}$ & $\mathrm{A}$ & 0 & 5.2 & 1.8 & 10.0 \\
\hline 14 & $\mathrm{~A}$ & $\mathrm{~T}$ & G & $\mathrm{A}$ & $\mathrm{C}$ & $\mathrm{T}$ & G & G & $\mathbf{G}$ & $\mathrm{G}$ & $\mathrm{T}$ & $\mathrm{A}$ & 0 & 1.7 & 0 & 0 \\
\hline 15 & $\mathrm{~A}$ & $\mathrm{~T}$ & G & $\mathrm{A}$ & $\mathrm{C}$ & $\mathrm{T}$ & G & G & G & $\mathrm{T}$ & $\mathrm{C}$ & $\mathrm{A}$ & 2.0 & 0 & 0 & 5.0 \\
\hline 16 & $\mathrm{~A}$ & $\mathrm{~T}$ & G & $\mathrm{A}$ & $\mathrm{C}$ & $\mathrm{T}$ & G & G & $\mathbf{G}$ & $\mathrm{T}$ & $\mathrm{T}$ & $\mathrm{T}$ & 2.0 & 0 & 0 & 0 \\
\hline 17 & $\mathrm{~A}$ & $\mathrm{~T}$ & $\mathrm{G}$ & $\mathrm{A}$ & C & $\mathrm{T}$ & $\mathrm{G}$ & $\mathrm{A}$ & $\mathbf{G}$ & $G$ & $\mathrm{C}$ & A & 0 & 1.7 & 0 & 0 \\
\hline 18 & $\mathrm{~A}$ & $\mathrm{~T}$ & $G$ & $\mathrm{~A}$ & $\mathrm{~A}$ & $\mathrm{~T}$ & A & G & $\mathrm{A}$ & $G$ & $\mathrm{C}$ & A & 2.0 & 1.7 & 3.6 & 5.0 \\
\hline 19 & A & $\mathrm{T}$ & G & A & A & $\mathrm{T}$ & A & G & A & $\mathrm{T}$ & C & A & 0 & 0 & 3.6 & 0 \\
\hline 20 & A & $\mathrm{T}$ & G & A & A & $\mathrm{T}$ & A & G & G & G & C & A & 4.0 & 5.2 & 3.6 & 0 \\
\hline 21 & A & $\mathrm{T}$ & G & A & A & $\mathrm{T}$ & A & $G$ & G & $\mathrm{T}$ & C & A & 8.0 & 5.2 & 0 & 5.0 \\
\hline 22 & A & $\mathrm{T}$ & G & A & A & $\mathrm{T}$ & A & G & G & $\mathrm{T}$ & $\mathrm{T}$ & A & 0 & 1.7 & 0 & 0 \\
\hline 23 & A & $\mathrm{T}$ & G & G & C & $\mathrm{T}$ & A & G & G & $\mathrm{T}$ & C & A & 0 & 0 & 0 & 2.5 \\
\hline 24 & A & $\mathrm{T}$ & G & G & A & $\mathrm{T}$ & A & G & A & G & C & A & 0 & 5.2 & 0 & 12.5 \\
\hline 25 & A & $\mathrm{T}$ & G & G & A & $\mathrm{T}$ & A & $G$ & G & G & C & A & 6.0 & 5.2 & 7.1 & 0 \\
\hline 26 & A & $\mathrm{T}$ & G & G & A & $\mathrm{T}$ & A & $G$ & G & $\mathrm{T}$ & C & A & 6.0 & 0 & 0 & 0 \\
\hline 27 & A & $\mathrm{T}$ & A & G & A & $\mathrm{T}$ & A & G & A & G & C & A & 0 & 1.7 & 0 & 0 \\
\hline 28 & A & $\mathrm{T}$ & A & G & A & $\mathrm{T}$ & A & G & G & G & C & A & 2.0 & 1.7 & 7.1 & 5.0 \\
\hline 29 & $\mathrm{~A}$ & $\mathrm{~T}$ & A & G & $\mathrm{A}$ & $\mathrm{T}$ & A & G & G & $\mathrm{T}$ & $\mathrm{C}$ & A & 0 & 0 & 0 & 2.5 \\
\hline
\end{tabular}

Примечание. № - номер гаплотипов, сформированных аллельными вариантами локусов, указанных в том же порядке, как в табл. 1. Сокращения: СВС - Северо-Восточная Сибирь, ЦС - Центральная Сибирь, ЮС - Южная Сибирь, ЗС Западная Сибирь. Вариант rs2228570-G выделен полужирным шрифтом. 
типов: гаплотипы 1-8 и 9-29, различающиеся по локусам rs2853562, rs9729 и rs739837 (под номерами 1, 2 и 6 в табл. 4). Таким образом, высокая частота варианта rs2228570-G в выборке из Центральной Сибири, по всей видимости, не связана с отбором какого-либо одного гаплотипа гена $V D R$, хотя стоит отметить несколько повышенную частоту гаплотипа 2 (44.8\%) (см. табл. 4).

Полученные в настоящей работе данные о распространенности вариантов полиморфизма гена $V D R$ в популяциях Сибири, к сожалению, основаны на результатах исследований выборок небольшого размера. Поэтому полученные выводы, скорее, определяют направления будущих более масштабных исследований полиморфизма гена $V D R$ и особенностей распределения аллельных вариантов в популяциях коренного населения Сибири.

Проведенное исследование показало, что распределение аллельных вариантов гена $V D R$ (в частности, по локусу rs2228570) у коренного населения Сибири может иметь региональный характер. Так, в соответствии с полученными результатами исследования региональных выборок населения у коренных жителей Центральной Сибири можно ожидать повышение частоты варианта rs2228570-G, а у жителей Северо-Восточной Сибири, наоборот, понижение частоты этого варианта. Следует отметить, что ранее уже обсуждалась проблема распределения аллельных вариантов локуса rs2228570 в связи с адаптацией коренного населения Урала и Сибири к различным экологическим условиям (Козлов и др., 2013, 2019). Например, у шорцев, проживающих в условиях с низкой доступностью витамина D и кальцийсодержащих продуктов, были обнаружены повышенные частоты варианта rs2228570-G (до $66.2 \%$ ), что объяснялось необходимостью повышения чувствительности рецепторов тканей к витамину D (Козлов и др., 2019). У коренного населения Ямало-Ненецкого автономного округа (ненцев, селькупов, хантов) самое низкое содержание витамина D в сыворотке крови обнаружено у носителей аллеля rs2228570-G (71.1\%) и генотипа rs2228570-GG (52.6\%) (Батурин и др., 2017). Между тем исследование китайских пациентов с дефицитом витамина D, получавших в течение 20 недель витамин D3 (2000 ед./сут), показало, что максимальное увеличение содержания витамина D наблюдалось у носителей генотипа rs2228570-GG (Yao et al., 2017). Таким образом, по всей видимости, вариант rs2228570-G гена $V D R$ наиболее выгоден в условиях дефицита витамина D. B таком случае можно ожидать, что у народов, традиционная диета которых характеризуется высоким содержанием витамина D в мясе и жире морских млекопитающих и рыб, будут наблюдаться самые низкие частоты варианта
rs2228570-G. Собственно это и наблюдается, поскольку в выборке из Северо-Восточной Сибири, представленной эскимосами, чукчами и коряками, зарегистрированы более низкие в сравнении с соседними центрально-сибирскими народами частоты этого варианта - 57\% против 81. Аналогично частота генотипа rs2228570-GG на северовостоке почти в 2.5 раза ниже, чем в центральносибирской выборке (29 против 69\%).

Тем не менее вопрос о связи полиморфизма гена $V D R$ с уровнем обеспеченности организма витамином D является очень сложным и многогранным (Козлов, Атеева, 2011). В отношении коренного населения арктических и субарктических регионов, сформировавшегося в результате долговременной адаптации к условиям Крайнего Севера, вполне возможно, что пониженное, по «европейским» стандартам, содержание витамина D в сыворотке крови (например, у эскимосов) не свидетельствует о его дефиците, а указывает на возникший адаптивным путем механизм снижения потребностей в витамине D (Rejnmark et al., 2004; Frost, 2012). Предполагается, что негативные последствия низкого содержания витамина D в крови у эскимосов могут компенсироваться двумя путями: либо за счет увеличения скорости превращения транспортной формы витамина D в гормональную форму (т. е. превращения 25(OH)D в 1.25(OH) D) (Rejnmark et al., 2004), либо за счет более эффективного связывания витамина D с рецепторами VDR (Sellers et al., 2003; Frost, 2012). О популяционной специфике генетических детерминант D-витаминного обмена свидетельствуют результаты исследования влияния геномного полиморфизма на метаболизм витамина D у эскимосов Аляски (Aslibekyan et al., 2016). В этой работе было показано, что к различиям по содержанию витамина D в сыворотке крови у эскимосов могут быть причастны несколько регионов на хромосомах 2, 10 и 22, а также кандидатные гены $M X D 1$ и $N E B L$. Таким образом, вполне возможно, что в регуляции метаболизма витамина D в популяциях человека, населяющих различные природноклиматические зоны, задействованы различные гены и генные комплексы, идентифицировать которые еще предстоит в более детальных исследованиях на региональном, этническом и популяционном уровне.

\section{ЛИТЕРАТУРА}

Батурин А. К., Сорокина Е. Ю., Вржесинская О. А., Бекетова Н. А., Сокольников А. А., Кобелькова И. В., Кешабяни Э. Э., Коденцова В. М., Макурина $O$. Н., Пескова E. B. Изучение связи генетического полиморфизма rs2228570 гена $V D R$ с обеспеченностью витамином D у жителей российской Арктики // Boпросы питания. 2017. Т. 86, № 4. С. 77-84. 
Громова О. А., Ториин И. Ю., Спиричев В. Б. Полногеномный анализ сайтов связывания рептора витамина D указывает на широкий спектр потенциальных применений витамина D в терапии // Медицинский совет. 2016. № 1. С. 12-21.

Козлов А. И., Атеева Ю. А. Витамин D и особенности питания различных групп коми // Вестник Московского университета. Сер. 23. Антропология. 2011. № 4. C. 25-34.

Козлов А. И., Вершубская Г. Г., Атеева Ю. А., Орр П., Лакомб Л. Ассоциация полиморфизма гена витамина D c антропометрическими показателями в группе этнических коми // Экологическая генетика. 2013. T. 11, № 2. C. 41-49.

Козлов А. И., Вершубская Г. Г., Негашева М. А. Полиморфизм гена рецептора витамина D (VDR) в выборках населения Европейской России и Приуралья // Пермский медицинский журнал. 2016. T. 23, № 5. Р. 60-66.

Козлов А. И., Остроухова И. О., Лавряшина М. Б., Вершубская Г. Г., Ульянова М. В. Антропоэкологическая специфика полиморфизма генов, влияющих на метаболизм костной ткани (на примере популяции шорцев) // Вестник Московского университета. Сер. 23. Антропология. 2019. № 2. С. 107-115.

Малярчук Б. А., Деренко М. В., Денисова Г. А., Литвинов $A$. Н. Распространенность арктического варианта гена $C P T 1 A$ в популяциях коренного населения Сибири // Вавиловский журнал генетики и селекции. 2016. T. 20, № 5. С. 571-575.

Ames S. K., Ellis K. J., Gunn S. K., Copeland K. C., Abrams, S. A. Vitamin D receptor gene Fok1 polymorphism predicts calcium absorption and bone mineral density in children // Journal of Bone and Mineral Research. 1999. Vol. 14. P. 740-746.

Arai H., Miyamoto K., Taketani Y., Yamamoto H., Iemori Y., Morita K., Tonai T., Nishisho T., Mori S., Takeda E. A vitamin $\mathrm{D}$ receptor gene polymorphism in the translation initiation codon: effect on protein activity and relation to bone mineral density in Japanese women // Ibid. 1997. Vol. 12. P. 915-921.

Aslibekyan S., Vaughan L. K., Wiener H. W., Hidalgo B. A., Lemas D. J., O'Brien D. M., Hopkins S. E., Stanhope K. L., Havel P. J., Thummel K. E., Boyer B. B., Tiwari $H$. K. Linkage and association analysis of circulating vitamin $\mathrm{D}$ and parathyroid hormone identifies novel loci in Alaska Native Yup'ik people // Genes \& Nutrition. 2016. Vol. 11. P. 23.

Clemente F. J.,Cardona A., Inchley C. E., Clemente F. J., Cardona A., Inchley C. E., Peter B. M., Jacobs G., Pagani L., Lawson D. J., Antão T., Vicente M., Mitt M., DeGiorgio M., Faltyskova Z., Xue Y., Ayub Q., Szpak M., Mägi R., Eriksson A., Manica A., Raghavan M., Rasmussen M., Rasmussen S., Willerslev E., Vidal-Puig A., TylerSmith C., Villems R., Nielsen R., Metspalu M., Malyarchuk B., Derenko M., Kivisild T. A Selective Sweep on a Deleterious Mutation in the CPT1A Gene in Arctic Populations // American Journal of Human Genetics. 2014. Vol. 95. P. 584-589.

Excoffier L., Laval G., Schneider S. Arlequin (version 3.0): an integrated software package for population genet- ics data analysis // Evolutionary Bioinformatics Online. 2007. Vol. 1. P. 47-50.

Frost $P$. Vitamin D deficiency among northern Native Peoples: a real or apparent problem? // International Journal of Circumpolar Health. 2012. Vol. 71. P. 18001.

Jurutka P. W., Remus L. S., Whitfield G. K., Thompson P. D., Hsieh J. C., Zitzer H., Tavakkoli P., Galligan M. A., Dang H. T., Haussler C. A., Haussler M. R. The polymorphic $\mathrm{N}$ terminus in human vitamin $\mathrm{D}$ receptor isoforms influences transcriptional activity by modulating interaction with transcription factor IIB // Molecular Endocrinology. 2000. Vol. 14. P. 401-420.

Pagani L., Lawson D. J., Jagoda E., Mörseburg A., Eriksson A., Mitt M., Clemente F., Hudjashov G., DeGiorgio M., Saag L., Wall J. D., Cardona A., Mägi R., Wilson Sayres M., Kaewert S., Inchley C., Scheib C. L., Järve M., Karmin M., Jacobs G. S., Antao T., Iliescu F. M., Kushniarevich A., Ayub Q., Tyler-Smith C., Xue Y., Yunusbayev B., Tambets K., Mallick C. B., Saag L., Pocheshkhova E., Andriadze G., Muller C., Westaway M. C., Lambert D. M., Zoraqi G., Turdikulova S., Dalimova D., Sabitov Z., Sultana G. N. N., Lachance J., Tishkoff S., Momynaliev K., Isakova J., Damba L. D., Gubina M., Nymadawa P., Evseeva I., Atramentova L., Utevska O., Ricaut F. X., Brucato N., Sudoyo H., Letellier T., Cox M. P., Barashkov N. A., Skaro V., Mulahasanovic L., Primorac D., Sahakyan H., Mormina M., Eichstaedt C. A., Lichman D. V., Abdullah S., Chaubey G., Wee J. T. S., Mihailov E., Karunas A., Litvinov S., Khusainova R., Ekomasova N., Akhmetova V., Khidiyatova I., Marjanović D., Yepiskoposyan L., Behar D. M., Balanovska E., Metspalu A., Derenko M., Malyarchuk B., Voevoda M., Fedorova S. A., Osipova L. P., Lahr M. M., Gerbault P., Leavesley M., Migliano A. B., Petraglia M., Balanovsky O., Khusnutdinova E. K., Metspalu E., Thomas M. G., Manica A., Nielsen R., Villems R., Willerslev E., Kivisild T., Metspalu M. Genomic analyses inform on migration events during the peopling of Eurasia // Nature. 2016. Vol. 538. P. 238 242.

Rejnmark L., Jørgensen M. E., Pedersen M. B., Hansen J. C., Heickendorff L., Lauridsen A. L., Mulvad G., Siggaard C., Skjoldborg H., Sørensen T. B., Pedersen E. B., Mosekilde L. Vitamin D insufficiency in Greenlanders on a westernized fare: ethnic differences in calcitropic hormones between Greenlanders and Danes // Calcified Tissue International. 2004. Vol. 74. P. 255-263.

Sellers E. A., Sharma A., Rodd C. Adaptation of Inuit children to a low-calcium diet // Canadian Medical Association Journal. 2003. Vol. 168. P. 1141-1143.

Yao P., Sun L., Lu L., Ding H., Chen X., Tang L., Xu X., Liu G., Hu Y., Ma Y., Wang F., Jin Q., Zheng H., Yin H., Zeng R., Chen Y., Hu F. B., Li H., Lin X. Effects of genetic and nongenetic factors on total and bioavailable $25(\mathrm{OH})$ D responses to vitamin D supplementation // Journal of Clinical Endocrinology \& Metabolism. 2017. Vol. 102. P. 100-110.

Zenata O., Vrzal R. Fine tuning of vitamin D receptor (VDR) activity by post-transcriptional and posttranslational modifications // Oncotarget. 2017. Vol. 8. P. 35390-35402. 


\title{
POLYMORPHISM OF THE VITAMIN D RECEPTOR GENE IN ABORIGINAL POPULATIONS OF SIBERIA
}

\author{
B. A. Malyarchuk \\ Institute of Biological Problems of the North, FEB RAS, Magadan
}

\begin{abstract}
Based on our own and published data on whole-exome polymorphism in aboriginal populations of Siberia, we studied the variability of the vitamin D receptor gene (gene VDR), which plays an important role in the processes of calcium and phosphorus metabolism, calcium transport to bone tissue, immunomodulation, and regulation of cell energy metabolism. In exons, polymorphism was found in two positions: synonymous replacement in exon 9 (rs731236-G) and non-synonymous replacement in exon 2 (rs2228570-G), the latter being of functional significance. The highest frequencies of the rs2228570-G variant (81\%) were recorded in the Central Siberian sample (Evens, Evenks, Yakuts); the lowest (57\%), in the sample from Northeast Siberia (Eskimos, Chukchis and Koryaks) and intermediate (61\% and 63\%, respectively) in the South Siberian (Tuvinians, Shors, Altaians, Buryats) and West Siberian (Kets, Khanty, Mansi, Selkups, Nenets, Nganasans) samples. The maximum frequency of the homozygous rs $2228570-$ GG genotype $(69 \%)$ was detected in the Central Siberian sample. The frequency of $V D R$ gene polymorphism variants in aboriginal populations of Siberia is discussed in connection with adaptation to various environmental conditions.
\end{abstract}

Keywords: genetic polymorphism, vitamin D receptor gene (VDR), polymorphism of locus rs2228570, human populations, Siberia.

\section{REFERENCES}

Ames, S. K., Ellis, K. J., Gunn, S. K., Copeland, K. C., Abrams, S. A., 1999. Vitamin D Receptor Gene Fok1 Polymorphism Predicts Calcium Absorption and Bone Mineral Density in Children, Journal of Bone and Mineral Research. 14, 740-746.

Arai, H., Miyamoto, K., Taketani, Y., Yamamoto, H., Iemori, Y., Morita, K., Tonai, T., Nishisho, T., Mori, S., Takeda, E., 1997. A Vitamin D Receptor Gene Polymorphism in the Translation Initiation Codon: Effect on Protein Activity and Relation to Bone Mineral Density in Japanese Women, Ibid. 12, 915-921.

Aslibekyan, S., Vaughan, L. K., Wiener, H. W., Hidalgo, B. A., Lemas, D. J., O’Brien, D. M., Hopkins, S. E., Stanhope, K. L., Havel, P. J., Thummel, K. E., Boyer, B. B., Tiwari, H. K., 2016. Linkage and Association Analysis of Circulating Vitamin D and Parathyroid Hormone Identifies Novel Loci in Alaska Native Yup'ik People, Genes \& Nutrition. 11, 23.

Baturin, A. K., Sorokina, E. Yu., Vrzhesinskaya, O. A., Beketova, N. A., Sokol'nikov, A. A., Kobel'kova, I. V., Keshabyants, E. E., Kodentsova, V. M., Makurina, O. N., Peskova, Ye. V., 2017. The Study of the Association between rs2228570 Polymorphism of VDR Gene and Vitamin D Blood Serum Concentration in the Inhabitants of the Russian Arctic, Problems of Nutrition. 86, 4, 77-84 [In Russian].

Clemente, F. J., Cardona, A., Inchley, C. E., Clemente, F. J., Cardona, A., Inchley, C. E., Peter, B. M., Jacobs, G., Pagani, L., Lawson, D. J., Antão, T., Vicente, M., Mitt, M., DeGiorgio, M., Faltyskova, Z., Xue, Y., Ayub, Q., Szpak, M., Mägi, R., Eriksson, A., Manica, A., Raghavan, M., Rasmussen, M., Rasmussen, S., Willerslev E., VidalPuig, A., Tyler-Smith, C., Villems, R., Nielsen, R., Metspalu, M., Malyarchuk, B., Derenko, M., Kivisild, T., 2014. A
Selective Sweep on a Deleterious Mutation in the CPT1A Gene in Arctic Populations, American Journal of Human Genetics. 95, 584-589.

Excoffier, L., Laval, G., Schneider, S., 2007. Arlequin (version 3.0): an Integrated Software Package for Population Genetics Data Analysis, Evolutionary Bioinformation Online. 1, 47-50.

Frost, P., 2012. Vitamin D Deficiency Among Northern Native Peoples: a Real or Apparent Problem? International Journal of Circumpolar Health. 71, 18001.

Gromova, O. A., Torshin, I. Yu., Spirichev, V. B., 2016. Genome-Wide Analysis of the Vitamin D Receptor Binding Sites Indicates a Wide Range of Potential Applications of Vitamin D in Therapy, Medical Council. 1, 12-21 [In Russian].

Jurutka, P. W., Remus, L. S., Whitfield, G. K., Thompson, P. D., Hsieh, J. C., Zitzer, H., Tavakkoli, P., Galligan, M. A., Dang, H. T., Haussler, C. A., Haussler, M. R., 2000. The Polymorphic N Terminus in Human Vitamin D Receptor Isoforms Influences Transcriptional Activity by Modulating Interaction with Transcription Factor IIB, Molecular Endocrinology. 14, 401-420.

Kozlov, A. I., Ateeva, Ju. A., 2011. Vitamin D and Eating Habits in Various Groups of Komi, Moscow University Anthropology Bulletin. 4, 25-34 [In Russian].

Kozlov, A. I., Ostroukhova, I. O., Lavryashina, M. B., Vershubskaya, G. G., Ulyanova, M. V., 2019. Anthropological and Ecological Specificity of Polymorphism in Genes Related to Bone Tissue Metabolism (as Exemplified by the Shors People), Ibid. 2, 107-115 [In Russian].

Kozlov, A. I., Vershubskaya, G. G., Ateeva, Yu. A., Orr, P., Lacombe, L., 2014. Association of Vitamin D Receptor Gene with Anthropometric Measures in Komi Ethnic 
Group, Russian Journal of Genetics: Appl. Res. 4, 5, 397404.

Kozlov, A. I., Vershubskaya, G. G., Negasheva, M. A., 2016. Polymorphism of Vitamin D Receptor (VDR) Gene in Sampling of European Russia and Priuraliye Population, Perm Medical Journal. 33, 5, 60-66 [In Russian].

Malyarchuk, B. A., Derenko, M. V., Denisova, G. A., Litvinov, A. N., 2016. Distribution of the Arctic Variant of the CPT1A Gene in Indigenous Populations of Siberia, Vavilov Journal of Genetics and Breeding. 20, 5, 571-575 [In Russian].

Pagani, L., Lawson, D. J., Jagoda, E., Mörseburg, A., Eriksson, A., Mitt, M., Clemente, F., Hudjashov, G., DeGiorgio, M., Saag, L., Wall, J. D., Cardona, A., Mägi, R., Wilson Sayres, M., Kaewert, S., Inchley, C., Scheib, C. L., Järve, M., Karmin, M., Jacobs, G. S., Antao, T., Iliescu, F. M., Kushniarevich, A., Ayub, Q., Tyler-Smith, C., Xue, Y., Yunusbayev, B., Tambets, K., Mallick, C. B., Saag, L., Pocheshkhova, E., Andriadze, G., Muller, C., Westaway, M. C., Lambert, D. M., Zoraqi, G., Turdikulova, S., Dalimova, D., Sabitov, Z., Sultana, G. N. N., Lachance, J., Tishkoff, S., Momynaliev, K., Isakova, J., Damba, L. D., Gubina, M., Nymadawa, P., Evseeva, I., Atramentova, L., Utevska, O., Ricaut, F. X., Brucato, N., Sudoyo, H., Letellier, T., Cox, M. P., Barashkov, N. A., Skaro, V., Mulahasanovic, L., Primorac, D., Sahakyan, H., Mormina, M., Eichstaedt, C. A., Lichman, D. V., Abdullah, S., Chaubey, G., Wee, J. T. S., Mihailov, E., Karunas, A., Litvinov, S., Khusainova, R., Ekomasova, N., Akhmetova, V., Khidiyatova, I., Marjanović, D., Yepiskoposyan, L., Behar, D. M.,
Balanovska, E., Metspalu, A., Derenko, M., Malyarchuk, B., Voevoda, M., Fedorova, S. A., Osipova, L. P., Lahr, M. M., Gerbault, P., Leavesley, M., Migliano, A. B., Petraglia, M., Balanovsky, O., Khusnutdinova, E. K., Metspalu, E., Thomas, M. G., Manica, A., Nielsen, R., Villems, R., Willerslev, E., Kivisild, T., Metspalu, M., 2016. Genomic Analyses Inform on Migration Events during the Peopling of Eurasia, Nature. 538, 238-242.

Rejnmark, L., Jørgensen, M. E., Pedersen, M. B., Hansen, J. C., Heickendorff, L., Lauridsen, A. L., Mulvad, G., Siggaard, C., Skjoldborg, H., Sørensen, T. B.; Pedersen, E. B., Mosekilde, L., 2004. Vitamin D Insufficiency in Greenlanders on a Westernized Fare: Ethnic Differences in Calcitropic Hormones between Greenlanders and Danes, Calcified Tissue International. 74, 255-263.

Sellers, E. A., Sharma, A., Rodd, C., 2003. Adaptation of Inuit Children to a Low-Calcium Diet, Canadian Medical Association Journal. 168, 1141-1143.

Yao, P., Sun, L., Lu, L., Ding, H., Chen, X., Tang, L., $X u, X ., L i u, G ., H u, Y$., Ma, Y., Wang, F., Jin, Q., Zheng, H., Yin, H., Zeng, R., Chen, Y., Hu, F. B., Li, H., Lin, X., 2017. Effects of Genetic and Nongenetic Factors on Total and Bioavailable 25(OH)D Responses to Vitamin D Supplementation, Journal of Clinical Endocrinology \& Metabolism. 102, 100-110.

Zenata, O., Vrzal, R., 2017. Fine Tuning of Vitamin D Receptor (VDR) Activity by Post-Transcriptional and Post-Translational Modifications, Oncotarget. 8, 35390-35402. 